\title{
Pesquisa-intervenção, Cartografia e estágio SUPERVISIONADO NA FORMAÇÃO DE PROFESSORES
}

Rosimeri de Oliveira Dias $\star$

\section{Resumo}

O propósito deste trabalho é dar visibitlidade à constituição de uma cartografia conceitual em que seja possivel analisar o movimento do estágio supervisionado como uma política de formação de professores, bem como evidenciar as contribuições da pesquisa-intervenção e da cartografia para o campo da formação de professores. Para tanto, comparecem na discussão uma formação conceitual e metodológica por meio da cartografia e da pesquisa-intervenção; as análises dos diários de campo, tanto do professor quanto dos alunos e os signos forjados no decorrer de um semestre letivo. Neste contexto de análise discute-se uma formação inventiva pela constituição de uma estética da existência e o problema político do estágio supervisionado na formação de professores, tomando este problema numa dimensão micropolítica. Conclui-se que estas são ferramentas para o enfrentamento da complexidade da escola, assumindo-a como a constituição de um território movente que luta por ser usina e usuária de um conhecimento vivo.

Palavras-chave: pesquisa-intervenção; cartografia; estágio supervisionado; formação inventiva de professores; políticas de cognição.

\section{INTERVENTION-RESEARCH, CARTOGRAPHY AND SUPERVISED TRAINING PROGRAM IN THE TEACHER'S FORMATION}

\begin{abstract}
The aim of this study is to give visibility to the construction of a conceptual cartography, in which it is possible to analyse the movement of the supervised training program as a teachers' formation politics, as well as to make evident the contributions of the intervention-research and cartography for the teachers' formation area. For this purpose, a conceptual and methodological construction are presented in the discussion by means of the cartography and the interventionresearch; the analysis of the log books, both from the teacher as the students, and the notes created during the school semester. Within this context of analysis, the inventive formation is discussed by means of existence aesthetics constitution and the political problem of supervised training during teacher's formation, taking this problem under a micropolitical dimension. It can be concluded that these are tools for facing the complexity of the school, taking it as the constitution of a territory in movement, that struggles to be a factory and user of a living knowledge.

Keywords: intervention-research; cartography; supervised trainee program;

^ Doutora em Psicologia pela Universidade Federal do Rio de Janeiro, Professora Adjunta do Departamento de Educação da Faculdade de Formação de Professores da Universidade do Estado do Rio de Janeiro. Endereço: Universidade do Estado do Rio de Janeiro, Faculdade de Formação de Professores, São Gonçalo. Rua Francisco Portela, 794 Paraíso - Sao Goncalo, RJ - Brasil. CEP: 24435-000.

E-mail: rosimeri.dias@uol.com.br
\end{abstract}


inventive teacher's formation; cognitive politics.

"A escola, templo da formação em nossa cultura, será entendida como usuária e como usina do conhecimento" (ROCHA, 2007, p. 37).

O propósito deste trabalho é dar visibilidade à constituição de uma cartografia conceitual em que seja possível analisar o movimento do estágio supervisionado como uma política de formação de professores, bem como evidenciar as contribuições da pesquisa-intervenção e da cartografia para o campo da formação de professores. Para tanto, muitos atravessamentos comparecem na discussão, tais como: a formação conceitual e metodológica por meio da cartografia (na perspectiva de Gilles Deleuze e Felix Guattari) e da pesquisa-intervenção (na perspectiva de René Lourau), as análises dos diários de campo, ${ }^{1}$ tanto do professor quanto dos alunos e os signos forjados no decorrer do semestre, expressando processos de formação que polemizam os modos de gestão da própria formação. Isto significa dizer que formação, neste trabalho, não é pensada como dar forma ao futuro professor, mas, ao contrário, formação assume o desafio de "tensionar modelos rígidos e predeterminados, evidenciando a necessidade de não confundir uma forma de ensinar com o único modo de praticá-la" (DIAS, 2009, p. 164), assumindo, neste contexto, a dimensão de uma formação inventiva. ${ }^{2}$

\section{FormaÇão InVEntiva, POLÍtiCAS de COGNIÇÃo E ESTÉTICA DA EXISTÊNCIA}

É no meio polêmico dos estudos da cognição que se expressa uma formação inventiva. Formação esta emergente da ligação problematizada entre as redes de conhecimento e as políticas de cognição existentes na própria formação. $\mathrm{O}$ conceito de políticas de cognição busca evidenciar que o problema do conhecer não se esgota na sua definição teórica ou no debate acerca dos modelos ou paradigmas que se utiliza para seu entendimento. $\mathrm{O}$ problema do conhecer envolve uma posição em relação ao mundo e a si mesmo, uma atitude, um ethos. Pensando desta maneira, identificar a cognição ao modelo do processamento da informação, como faz o cognitivismo computacional, ${ }^{3}$ ou aproximá-la de um processo de invenção de si e do mundo, não constitui apenas uma divergência teórica, mas também uma distinção ética e política (KASTRUP; TEDESCO; PASSOS, 2008). Neste sentido, formar não é apenas dar forma, mas, muitas vezes, envolve também estratégias de desmanchamento de certas formas e políticas cognitivas cristalizadas, para dar lugar a outros modos de relação com o mundo, com as pessoas e consigo mesmo.

De início, afirmo que há um modo tradicional e "pedagogizante"4 de colocar a questão da formação de professores, dizendo que no momento em que o aluno e o professor se submetem ao conhecimento "desde sempre aí" eles se ligam ao conhecer que já está posto, ou à relação com o saber. Tal relação prendeos ao seu percurso de informação individualizante, que transmite e ensina um saber com o objetivo da manutenção e perpetuação do mesmo. Esta é a maneira cognitivista de colocar a questão da formação de professores, pensando-a como solução de problemas. 
É possível colocar o problema da formação de outro modo: não mais supondo inicialmente o direito ao acesso ao conhecimento, não mais estabelecendo de início essa ligação voluntária e contratual com a transmissão e com os especialismos "pedagogizantes", mas colocando-a como um deslocamento do formar como solução de problemas que anima a invenção de problemas no campo da formação de professores. Tal análise evidencia-se na experiência, como um ethos, num campo de relação de forças.

O que acontece é um cultivo do paradoxo entre aprendizagem e desaprendizagem no campo da formação de professores. Este cultivo consiste em manter vivo um campo problemático que tensiona as certezas, os apriorismos especialistas, e propõe uma atitude transversal de deslocamentos que necessita experienciar e ensaiar diariamente políticas de cognição. Isto implica alimentar encontros de formação que deem ênfase ao agenciamento. Para Deleuze e Parnet (2004), agenciamento é uma multiplicidade que comporta termos heterogêneos, numa unidade que é um cofuncionamento de uma máquina social.

Para cultivar paradoxalmente aprender e desaprender no agenciamento coletivo da formação de professores, é necessário animar uma experiência ensaiada em devir na linha do encontro. Este cultivar expressa um formar com, experienciar com, inventar com, aprender com, desaprender com. Neste contexto, é fundamental estar no meio para resistir às armadilhas das máquinas binárias, aquelas que se estendem no espelho das identificações e as que exprimem uma recognição. Ao contrário desta lógica, só se pode agenciar os cofuncionamentos extraindo da própria formação toda a desaprendizagem que ela contém, sem formar para, mas coformação forjando uma formação inventiva. Por isto a importância do cofuncionamento, pois professor e aluno, ao experienciarem uma formação inventiva, pensam em como manter vivo o campo problemático, questão pensada no deslocamento entre solução de problemas e invenção de problemas. E fundamental relembrar que professor e aluno não estão juntos, mas entre.

Para pensar com formação $e$ com política $e$ com cultivo do paradoxo ,é necessário fazer da experiência de formação inventiva uma ferramenta de pensar. Trata-se do múltiplo, uma multiplicidade que não está na totalidade. Uma multiplicidade que se agencia na arte do $e$, num gaguejar próprio da formação, num uso minoritário do formar, feito aqui por uma formação inventiva. Em tal formação evidencia-se a não aceitabilidade hegemônica de uma formação, mas, ao contrário, ela se afirma em termos de devir, no entre aprender $e$ desaprender, cultivando as formas de problematizar, sempre provisórias. Não se trata de dizer que toda formação é ruim, mas de colocar ou de seguir linhas mutáveis moventes numa atitude teórico prática concernente a não necessidade de "tecnizar" uma formação. E, para distinguir essa posição teórico-prática acerca da não necessidade da formação de professores como princípio de inteligibilidade de um ensino, de uma aprendizagem, é preciso pensar formação num território de forças moventes, estudá-la no percurso de uma estética da existência. Porque este caminho escapa da técnica de aplicação e se constitui, permanentemente, num gesto semiesboçado, como invenção de si e do mundo (KASTRUP, 1999). E, neste sentido, só é possí- 
vel pensá-lo pelos movimentos que o potencializam ou o fragilizam no contexto de uma experiência, de uma formação inventiva. Aqui, formação não procede nem de uma lei civil ,nem de uma prescrição, mas de arte (DIAS, 2009).

Uma formação inventiva é pensada pela constituição de uma estética da existência, do modo proposto por Michel Foucault (2006a). Interessado na questão do sujeito e sua relação com a verdade, Foucault (1985, 2004, 2006a, 2006b) aprofunda o tema da estética da existência em diferentes textos. Em suas análises das civilizações antigas, a preocupação residia em produzir uma vida livre pautada na afirmação da liberdade e na ética por meio de práticas. Fazendo uma distinção entre antiguidade e o cristianismo, Foucault (2006a) evidencia uma estética da existência. Tal estética faz ver e falar o momento em que as forças ativas dominam as forças que tendem à submissão. É neste espaço-tempo que a arte se produz e, ao mesmo tempo, forja uma vida bela e livre. A liberdade só é produzida no momento em que se dirige a vida por si mesmo.

A própria matéria de uma estética da existência aponta a capacidade de conduzir a vida liberta da moral em termos de juízo de valor. Foucault (2004) abre um campo de problematizações sobre as artes de viver. Não se trata de investigar uma vida de prazer ou de alegria entediada, mas sim governar a própria vida numa espécie de saber e de arte, em uma governabilidade implicada na relação de si consigo mesmo. Isto significa justamente que nessa noção de governabilidade o intuito é de um conjunto de práticas pelas quais é possível:

[...] constituir, definir, organizar, instrumentalizar as estratégias que os indivíduos, em sua liberdade, podem ter uns em relação aos outros. São indivíduos livres que tentam controlar, determinar, delimitar a liberdade dos outros e, para fazê-lo, dispõem de certos instrumentos para governar os outros (FOUCAULT, 2006b, p. 286).

Governabilidade, governar a si mesmo, não por uma moral normalizadora e dominante, mas pela capacidade de dar forma a si próprio e de modular seus próprios valores, gestos e fazeres.

É importante lembrar que, para Foucault, é na atualidade que se encontram as forças que agem na história. Chamado por Deleuze (2005) de um "historiador do presente", Foucault, em sua análise, opera uma concepção de tempo que distingue o tempo passado, lugar dos estratos históricos, e o tempo presente, em que este é o devir que faz a diferença na história. Quando investiga as estéticas da existência na experiência greco-romana, ele quer marcar uma diferença, um estranhamento em relação ao presente. E assim produz uma genealogia do sujeito que conduz a análise a partir de uma questão do presente.

Nesse sentido, as artes da existência situam-se na imanência da história em que as produções de subjetividade se constituem no tempo. É também ali, nas ações que contemplavam o cuidado com o outro, na constituição de si por meio de 
relações de amizade, de amor e de aprendizado, que elas se desfazem e se transformam. Trata-se para Foucault de investigar uma outra relação com as leis, as normas e a verdade, abrindo espaço-tempo de diferenciação da construção de si.

No agenciamento entre formação inventiva de professores, políticas de cognição e estéticas da existência, há o tangenciamento de uma micropolítica que se afirma pela diferença. A micropolítica é uma experimentação ativa, porque não se sabe antecipadamente como é que se desenha um ethos. No nível macropolítico de análise da formação, afirmam-se as representações dominantes das tradições curriculares e normativas, traduzidas em modelos a serem atingidos. As análises micropolíticas apontam para experiências concretas, em que se estabelecem os conflitos entre o vivido e os padrões de desempenho formulados a partir da lógica geral instituída.

Sendo assim, uma formação inventiva não é um conjunto de regras para serem aplicadas, nem um saber pronto para ser transmitido; não há uma receita geral, nem conceitos globalizantes. O que há são deslocamentos, entre formas e forças. Uma formação inventiva não é questão de aquisição de saber e de transmissão de informação. É preciso praticar uma formação inventiva. Neste contexto, a formação do professor não se fundamenta na experiência passada, mas encontra sua chave na experiência presente. Trata-se mais de um refinamento da percepção e da atenção do que um apelo ao saber acumulado ou à memória. É, acima de tudo, uma questão de aprendizado da sensibilidade ao campo de forças e às políticas que o atravessam. Trata-se de um cultivo da atenção concentrada e aberta à experiência de problematização. Passos, Kastrup e Escóssia (2009, p. 201) ajudam na articulação entre políticas de cognição e formação, quando falam da formação do cartógrafo:

Trata-se aqui do aprendizado da própria atenção ao presente vivo que é suscitada pela experiência da pesquisa, que assume aqui uma dimensão estética - estética porque diz respeito aos processos de criação da realidade. Ora, a atenção é como um músculo que, pelo exercício, produz regimes atencionais distintos e variados. Muitas vezes impera nas subjetividades a atenção recognitiva, mobilizada por interesses prévios e expectativas do pesquisador. O desafio é suspender sua hegemonia, em favor da atenção ao presente vivo das forças do território da pesquisa. Às vezes difícil no início, a atenção cartográfica vem a se tornar mais facilmente atualizada com a prática continuada, constituindo uma atitude cognitiva que cria condições atencionais mais propícias à prática da cartografia.

O problema das políticas de cognição no campo da formação de professores se alia à discussão mais geral da crítica aos especialismos e aposta na transdisciplinaridade como desestabilização do que se delimita como campo de uma disciplina. Por isso, uma política de formação de professores, de um modo geral, e o estágio supervisionado, num contexto mais especial, são atravessados por diferentes domínios, provocando interlocuções. Aceitando o desafio de pensar no 
limite entre os saberes, a transdisciplinaridade coloca em questão os objetos bem definidos do campo da formação e as teorias internamente consistentes, a preexistência de sujeitos do conhecimento e objetos a serem conhecidos, as escolas bem demarcadas das práticas, os especialistas defensores de territórios identitários de conhecimento. Com o tensionamento dos limites postos pela disciplinarização e a inserção das políticas de cognição no campo da formação, emerge o plano de constituição dos domínios do conhecimento, em que as dicotomias dão lugar às misturas e às bordas fronteiriças com um grau de abertura para a intervenção e a análise da emergência das práticas que visibilizam sua complexidade.

Para assumir o estágio supervisionado como uma direção política, é necessário cartografar sua direção metodológica num contexto transdisciplinar atravessado em uma política de cognição. Isto nos compromete com uma análise de processos em curso, acompanhando-os, porque habitamos um território ${ }^{6}$ existencial e aprendemos num contexto vivo e intenso, adotando uma atitude, um ethos no estágio. Habitar o território da formação e da escola não é apenas buscar soluções para problemas prévios, nem tampouco forjar novas tarefas para serem aplicadas na escola, mas envolve disponibilidade e abertura para o encontro com o inesperado, o que significa alterar prioridades e eventualmente redesenhar o próprio problema do aprender e do ensinar.

Se o aprendizado nos traz um ganho, se ele, em alguma medida nos forma, é no sentido da inscrição corporal do conhecimento. Nessa medida, para tornar-se cartógrafo não basta ler este livro ou outros textos teóricos sobre o assunto. É preciso praticar, ir a campo, seguir processos, lançar-se na água, experimentar dispositivos, habitar um território, afinar a atenção, deslocar pontos de vista e praticar a escrita, sempre levando em conta a produção coletiva do conhecimento. Na aventura cotidiana de uma pesquisa enfrentamos diversos riscos e podemos produzir cartografias melhores ou piores, excelentes ou simplesmente interessantes. Podemos também imaginar que cartografamos, quando apenas representamos. Nomear de cartografia o método que praticamos não garante o resultado de nosso trabalho. $\mathrm{O}$ rigor da investigação cartográfica reside na irredutível atenção aos movimentos da subjetividade e da paisagem existencial, suas pontas de presente, seus fios soltos, suas linhas de fuga em relação à estratificação histórica. (PASSOS; KASTRUP; ESCÓSSIA, 2009, p. 203).

Os autores pensam o método da cartografia como uma política de cognição. Acompanhando essa ideia, é possível afirmar o estágio supervisionado como uma política de formação docente. Política, micropolítica, porque se constitui como um ethos incorporado nas experiências de formar professores. Aqui, compartilho o exercício de habitar o território do estágio como educadora e cartógrafa, fazendo uso de ferramentas que me forçam a apostar em outros possíveis para as práticas de formação de professores. Frente ao presente vivo da disciplina de estágio supervisionado e do campo concreto da escola, como distinguir os ver- 
dadeiros problemas dos falsos problemas? Como traçar um campo problemático mantendo vivo um processo de invenção de si e do mundo, num território onde tudo já está dado de antemão?

Nesta dimensão da formação de professores, composta por invenção, políticas de cognição e uma estética da existência, afirmo o estágio na feitura de uma micropolítica. $\mathrm{O}$ que significa dar ênfase às análises das circunstâncias em que nos produzimos, aos modos de subjetivação, a uma multiplicidade de formas e de forças: formas denominadas por Guattari e Rolnik (2005) de molares (dadas pelas representações que conhecemos e delimitam o formar, o como fazer a aula, a escola, a profissão, o formando...); forças denominadas, também por estes autores, de intensivas (com graus de afecção, de potência disruptora dos lugares determinados, de papéis e funções que demarcam modos de existências fixos, que fragilizam as divisões já instituídas, fazem o paradoxo das desaprendizagens ressoar em nós, desestabilizando formas de estagiar). "O problema de uma micropolítica é justamente o de nunca usar um só modo de referência" (GUATTARI; ROLNIK, 2005, p. 154). No contexto micropolítico tanto da formação de professores como do estágio supervisionado, lançam-se as problematizações. Como um corpo sensível, as práticas em constituição situam-se exatamente no cruzamento entre esses diferentes modos de apreensão de uma problemática.

A questão micropolítica - ou seja, a questão de uma analítica das formações do desejo no campo social - diz respeito ao modo como o nível das diferenças sociais mais amplas (que chamei de "molar") se cruza com aquele que chamei de "molecular". Entre esses dois níveis, não há uma oposição distintiva, que dependa de um princípio lógico de contradição. Parece difícil, mas é preciso simplesmente mudar de lógica. $\mathrm{Na}$ física quântica, por exemplo, foi necessário que um dia os físicos admitissem que a matéria é corpuscular e ondulatória, ao mesmo tempo. Da mesma forma, as lutas sociais são, ao mesmo tempo, molares e moleculares. (GUATTARI; ROLNIK, 2005, p. 149).

A questão micropolítica no campo da formação e do estágio docente, portanto, não é se deve-se ou não se organizar, e sim se está-se ou não reproduzindo os modos de subjetivação estratificados e hegemônicos que os mantêm tutelados por uma única referência de os fazer. É nestes termos que se coloca uma estética da existência na formação, na constituição de uma vida livre. Ela se expressa numa micropolítica que tem a ver com possibilidades de os agenciamentos na formação levarem em consideração as produções de subjetividade na escola, problemáticas essas geralmente deixadas de lado nos repertórios curriculares dos estágios.

Uma micropolítica, assim, envolve questões éticas, estéticas e políticas, trazendo-as para as análises dos problemas e dos impasses do mundo presente, do mundo em que estamos. O campo a ser analisado é da maior seriedade. As 
experiências a serem criadas, por outro lado, são incorporadas num porvir. Ainda há muito que fazer, sempre, em nossa constante luta para realizar, no dia a dia, um modo de vida inventivo.

Atenta ao presente, e habitando o território da escola e da formação, penso na necessidade de ferramentas para enfrentar a vida do modo como ela comparece, com seus contornos caóticos incorporados em nossa existência. O que tenho visto, frequentemente, são alunos e professores sem ferramentas para enfrentar as intensidades de um presente que, por não estar dado, precisa ser cartografado.

\section{ESTÁGIO SUPERVISIONADO, CARTOGRAFIA E PESQUISA INTERVENÇÃO: ENUNCIANDO}

\section{E VISIBILIZANDO OUTROS POSSÍVEIS DE FAZER UMA FORMAÇÃO DE PROFESSORES}

A autogestão não é estudável em manuais; é uma construção política permanente que se apoia, principalmente, sobre a restituição. A restituição também não significa confissão privada ou pública, como em situações religiosas, mas consiste em se centrar numa tarefa - a de análise coletiva da situação presente, no presente - em função das diversas implicações de cada um com e na situação. É um dispositivo relativamente aberto, mas não tão aberto quanto uma casa vazia com janelas quebradas e sem teto. (LOURAU, 1993, p. 64).

Acredito que o primeiro dia de aula de um professor seja um marco de extrema importância que será marcado pelo resto de nossas vidas, e um dos fatores que nos vai aumentando ao longo de nossa caminhada acadêmica com a proximidade de disciplinas voltadas para a familiarização com o espaço escolar e a expectativa para decodificar e buscar entender esse ambiente tão dinâmico que são os colégios (expectativa de um aluno quanto à disciplina e ao estágio supervisionado).

Neste momento do texto ,optamos por compartilhar uma experiência que aconteceu no primeiro semestre de 2009, na disciplina Estágio Supervisionado I, na FFP/UERJ. Por meio dela, usamos os conceitos ferramentas da cartografia e da pesquisa-intervenção, pois entendemos que estes funcionam como intercessores para pensar a formação docente como uma produção política permanente, como uma instituição. Para Lourau (1993), a instituição não é uma edificação, mas um território movente em que é necessário colocar em análise os processos instituídos e instituintes. É um devir. Nas palavras do autor: “[...] instituição não é uma coisa observável, mas uma dinâmica contraditória construindo-se na [e em] história, ou tempo. [...] É o devir, a história, o produto contraditório do instituinte com o instituído, em luta permanente, em constante contradição com as forças de autodissolução" (LOURAU, 1993, p. 11-12).

Neste jogo de relações de forças, fomos constituindo um território de constante autodissolução, tensionando a heterogestão com a autogestão, colocando em análise nossa implicação com a constituição de um novo campo de referência. 
Tarefa muito árdua para aqueles que se acostumam a "confiar" sua autogestão a outras pessoas, como nos chama a atenção René Lourau. O olhar do lugar também mantém a lógica da produção de quem concebe e quem faz.

Parafraseando Lourau (1993, p.14), escola é uma instituição que funciona, em grande parte, por prescritividades e racionalizações, sob o domínio da heterogestão, ou seja, gerida por outrem. "E a vivemos, geralmente, como coisa natural" (LOURAU, 1993, p. 14). Pretendendo-se científica, aceita o instituído como natural, como se alunos, professores e comunidade tivessem uma natureza de dominados, como se estivessem submetidos a outrem (direção, coordenação, secretarias....). Como se houvesse uma instância superior que naturalmente detém a propriedade privada da gestão escolar.

As racionalizações da heterogestão, em geral, as pensamos insuperáveis. Talvez porque não tenhamos, ainda conseguido efetivamente inventar a autogestão. A autogestão que existe, a que tem podido existir, acontece dentro da contradição total, já que a vida cotidiana, a minha e também a de vocês, se passa no terreno da heterogestão (LOURAU, 1993, p.14).

A máquina que rege a análise institucional da disciplina Estágio Supervisionado I é sua constituição política. Nesta análise, utilizo a restituição, que é um dispositivo sobre o qual se apoia a autogestão. A tarefa da restituição constitui-se numa análise de implicação, que afirma uma desnaturalização do processo, colocando a instituição - formação - nos constantes tensionamentos de uma construção permanente. Inclusive, possibilita a transformação do instituído, construindo, assim, um novo campo de coerência.

Pesquisa-intervenção constitui-se como crítica a políticas de pesquisa positivista, afirmando o ato político em que consiste toda investigação. "Acentuase todo o tempo o vínculo entre a gênese teórica e a gênese social dos conceitos, que é negado implícita ou explicitamente nas versões positivistas 'tecnológicas' de pesquisa" (RODRIGUES; SOUZA, 1987, p. 31 apud ROCHA; AGUIAR, 2003, p. 5). Para Rocha e Aguiar (2010), a aposta da pesquisa-intervenção tem favorecido uma aventura por outras formas de pensar e fazer pesquisas, numa perspectiva ético-estético-política. Inclusive, as autoras afirmam que tal perspectiva ganha consistência na micropolítica da produção de modos de subjetivação, e é evidenciada nas práticas de formação no contexto da educação por um tríplice objetivo, a saber:

(i) pensar a formação como criação de percursos em meio a múltiplas forças; (ii) remeter à reflexão sobre nossos atos, nossas implicações com as instituições em jogo, favorecendo escolhas sobre a melhor forma de viver; (iii) colocar em desafio de (re)constituição de um campo de intervenção, problematizador e crítico, intensificador de encontros (ROCHA; AGUIAR, 2010, p. 69). 
Nesse sentido, a pesquisa-intervenção intensifica a ruptura com modos tradicionais de pesquisa e amplia as bases teórico-metodológicas das pesquisas participativas, surgindo como proposta de atuação transformadora nas políticas, já que propõe uma intervenção de ordem micropolítica na experiência.Trata-se de um método que forja uma atitude de pesquisar, que afirma a ideia de intervenção na relação sujeito/objeto pesquisado, pois ambos se constroem na trajetória, considerando que esta interferência não se constitui como uma dificuldade própria às pesquisas no campo da formação de professores a ser justificada no tratamento dos dados. Ou seja, uma vez que é na relação das políticas de pesquisa que se configura a condição do próprio conhecimento, não há neutralidade nem objetividade a ser perseguida. Com efeito, a pesquisa-intervenção afirma seu caráter desarticulador dos discursos instituídos, inclusive os produzidos como científicos, substituindo a fórmula "conhecer para transformar" por "transformar para conhecer" (COIMBRA, 1995, apud ROCHA; AGUIAR, 2003, p. 6). Para tanto, o dispositivo do diário de campo, na perspectiva proposta por Lourau (1993), nos auxilia a cartografar os processos em curso.

E foi no contexto desse turbilhão conceitual que propus à turma iniciar o semestre.

Hoje é 1 de abril de 2009, padronizado culturalmente como o dia da mentira. Quando eu era criança achava que nesse dia não deveria haver aula, porque tudo o que fosse dito pelos professores poderia ser mentira, como se tudo o que é dito pelos professores fossem verdades absolutas e inquestionáveis. [...] Mas hoje, não sei se é muito pretensioso da minha parte, mas me sinto um pouco mais aberto às mudanças. Então, o que chamou a atenção hoje não foram só as minhas reações, mas as de todos da turma, não sei se foram semelhantes à minha, mas quero descobrir. Eu quero saber se eles sentem essa agonia ao pensar na vida sem uma verdade única. Assim, a agonia dá lugar ao medo de trocar o que já estar em vigor, pois afirmar o que já é hegemônico é muito fácil (diário de campo de um aluno).

Vou começar o meu relato a partir do primeiro dia de aula, quando a professora propôs a confecção de um diário de bordo. A princípio achei estranho, pois não tinha esse hábito desde a minha infância, quando era mais do que normal escrever sobre nossos sentimentos, impressões e expectativas. Características que infelizmente perdemos com o tempo muito em razão do nosso endurecimento (diário de campo de um aluno).

A aula acontece ensaiada, produzindo uma pequena inspiração com os textos e escrituras que fui fazendo no decorrer da 
vida. Uma aula agenciada com a intensidade espaço-temporal de habitar um novo território - estágio supervisionado - e, ao mesmo tempo, afirmar a disciplina pelo rizoma, pela criação de uma cartografia conceitual. Esta se executa numa expressão sensível dos campos em permanente movimento (diário de campo da professora).

O desafio foi lançado, e embarcamos na produção da cartografia conceitual, com tudo que ela nos afeta e exige de nós. Inclusive a dificuldade em tecer uma escrita incorporada e implicada na experiência. Os textos forçavam o pensamento a pensar, mas a dificuldade em sair do lugar da heterogestão foi expressa pelos gestos de silenciamentos, de não leitura, entre outros. Por isso optei por fazer a restituição pela escrita, como o próprio Lourau (1993, p. 70) analisa:

A restituição escrita, consequentemente, desempenha um papel em dois planos. Por um lado, ela deveria ser a restituição de todo o processo, açambarcando inclusive as coisas que, em geral, não são inscritas como necessárias, mas que, como vimos, fazem parte do campo produzido pelo pesquisador para realizar o ato de pesquisar; por outro, ser a restituição do próprio pensar/redigir (isto porque a redação supõe a aprendizagem de um código técnico-cultural determinado e desempenha, em nossa cultura, o papel de produzir, e permitir, um certo tipo de pensar). Evidentemente, o ato de pensar independe da escrita, mas o pensar escolarizado uma de nossas marcas culturais - e é desse que falamos, está diretamente relacionado à apreensão da mesma. A instituição acadêmico-científica nos faz escrever e escrevemos para sermos validados e valorizados por ela. A produção de nossos textos, o meu e o de vocês, está portanto implicada com a existência de tal instituição. Sequer aquilo que pensamos estar "naturalmente observando" é natural... Se refletirmos sobre o fato de, pelo menos, $49 \%$ da população alfabetizada não entender sobre o que escrevemos, teremos talvez a prova de que somos um artifício completo. Quer dizer, por mais que não o admitamos, escrevemos sempre para, e por, uma pequena comunidade de pesquisadores, e só. Tal aspecto, durante muito tempo naturalizado, do texto institucional começou a ser questionado quando do desvelamento de diários da pesquisa de campo (fato ainda muito recente no cenário acadêmico-científico).

Como já esperava, a resistência - como oposição - foi forte. Mas o trabalho na disciplina acontecia a favor da resistência - como criação - e esta tensionou o lugar comum do dito professor solucionador de problemas, pensado hegemonicamente nos postulados da formação como aquele que faz funcionar a máquina de propagação da informação e da explicação. O lugar comum da explicação comporta dois âmbitos indissociados. Um produz certo conforto no aprender, de 
modo que o aluno se sente atendido com a explicação do mestre, produzindo com isso um consenso. Em segundo lugar, freia o esforço do pensamento, pois quando o professor explica ao mesmo tempo em que ele diz o que é, ele forja no aluno a impossibilidade de pensar por si mesmo. Nesta perspectiva, a explicação embota o processo de invenção de problemas, muito caro para uma formação inventiva.

Seria preciso agora pensar a questão do comum, tão importante quando se considera um grupo, uma sociedade, um conjunto humano. Uma constatação trivial é evocada com insistência por vários autores contemporâneos, entre eles Toni Negri, Giorgio Agamben, Paolo Virno, JeanLuc Nancy, ou mesmo Maurice Blanchot. A saber, a de que vivemos hoje uma crise do "comum". As formas que antes pareciam garantir aos homens um contorno comum, e asseguravam alguma consistência ao laço social, perderam sua pregnância e entraram definitivamente em colapso, desde a esfera dita pública, até os modos de associação consagrados, comunitários, nacionais, ideológicos, partidários, sindicais. Perambulamos em meio a espectros do comum: a mídia, a encenação política, os consensos econômicos consagrados, mas igualmente as recaídas étnicas ou religiosas, a invocação civilizatória calcada no pânico, a militarização da existência para defender a "vida" supostamente "comum", ou, mais precisamente, para defender uma forma de vida dita "comum". No entanto, sabemos bem que essa "vida" ou "forma de vida" não é realmente "comum", que quando compartilhamos esses consensos, essas guerras, esses pânicos, esses circos políticos, esses modos caducos de agremiação, ou mesmo esta linguagem que fala em nosso nome, somos vítimas ou cúmplices de um seqüestro (PÉLBART, 2008, p. 3).

A ideia do comum analisada por Pélbart elucida a lógica de explicação no campo da formação, que totaliza modos de produzir aulas, sequestrando e colocando alunos e professores como cúmplices de políticas cognitivas que mantêm vivas práticas de solução de problemas. Tais práticas essencializam formas únicas de fazer a vida na formação e na escola, propagando a ideia de competências e habilidades em manuais, currículos, Plano Nacional de Desenvolvimento... Este modo de fazer a formação sequestra dos formandos e dos professores seus territórios de pensamento. Diferente desta dimensão explicadora, é possível tecer territórios de formação implicados com um espaço-tempo de pensamento. Como dito anteriormente, lutamos para dar visibilidade a ferramentas afetas à constituição de territórios de pensamento, que lutam para entender escola e formação como usuárias e usinas do conhecimento.

Contrária a um modo explicativo de fazer a formação, me encontrava às quartas, 7 h30 da manhã. Hora combinada, mas que funcionava como a insistência de se opor às regras, às normas, aos horários, e afirmava o lugar implicado da turma a cada encontro. Questão colocada em análise, pois penso que fala não 
de descompromisso, mas de resistência. Contudo, afirmava o lugar da implicação ética com uma formação que é política e preocupada com um aprender mais inventivo (DIAS, 2009). Ou seja, o desafio diário era evidenciar, nas práticas da disciplina, as lógicas contrárias às naturalizações e totalizações do saber absoluto. Com isto, o intuito era operar nas práticas. Não para aproximar teoria e prática, mas para evidenciar as práticas e suas relações de forças existentes no próprio ato de se formar, de pesquisar e de habitar o território da escola.

Sentia a força dos textos ${ }^{7}$ funcionando a favor da resistência como criação, mas a heterogestão falava muito alto e insistia em manter os formandos no lugar comum da representação.

Acordei às 5 h00 sem o relógio tocar, com uma sensação de susto e já pensando nos materiais da aula que não deixei organizados para a manhã. Na semana passada cheguei e solicitei TV e DVD para passar a letra Q de questão do abecedário de Deleuze. Cheguei na sala às $7 \mathrm{~h} 30$, como combinado com a turma, mas, numa semana intercalada por dois feriados, não havia alunos. Então, mudei de posição e resolvi fazer um resumo no quadro do texto do rizoma e da cartografia sentimental. O senhor da TV me interrompeu, falando que não há "quorum", e disse-lhe, numa conversa amistosa, que estava fazendo minha parte. Por volta das 7 h45 chegou o primeiro aluno, e em seguida mais nove alunos, totalizando 11 alunos (com a presença do bolsista). Então, iniciamos a discussão fazendo uma ressonância dos três textos, a saber: rizoma, cartografia sentimental e pistas da cartografia. Tracei um quadro analítico dos mesmos, evidenciando seus princípios. O efeito do quadro foi visível, didaticamente falando. Fui interrompida em minha escrita por um aluno para falar sobre o dispositivo (diário de campo da professora, 22/4/09).

A força do dispositivo ${ }^{8}$ quadro se colocou na prática como uma força para analisar as ressonâncias cotidianas com o grau de abertura do cartógrafo para viver a experiência, com uma prática que é política e com a criação do cotidiano de formação, que faz os movimentos do instituído - uso do quadro pelo professor - se transformarem em uma potente linha de invenção da existência. Ou seja, afirmar que o dito "cuspe e giz" é ultrapassado, é naturalizar um saber no seu lugar comum, sequestrando a potência do pensamento nas práticas, com seus usos e seus efeitos.

Já no dia 22/04/2009 a aula foi iniciada retomando os conceitos abordados anteriormente a partir de pontos relevantes descritos no quadro negro pela professora (rizoma e seus princípios/ manual do cartógrafo/ método cartografia). Após realizar os comentários, iniciamos as ponderações acerca do texto: "O método da cartografia e os quatro níveis 
da pesquisa-intervenção" de Virginia Kastrup. Dentre eles, a professora enfatizou o ato de cartografar, tecer um registro de diário de campo. Sendo assim, recorreu a Kastrup, onde a autora afirma que a preparação dos textos é um momento crucial de um trabalho de pesquisa, pois é através dos textos que o conhecimento produzido será tornado público e assim poderá ser conhecido para além de seu contexto específico. [...] É importante lembrar da "melhor" dinâmica que houve nessa aula, a meu ver, o uso do quadro pela professora ao descrever e pontuar os assuntos abordados. Foi um método didático que causou maior entendimento por parte dos alunos do assunto que estava sendo então tratado. A professora até então não tinha utilizado o quadro como ferramenta em nossos encontros, porém percebi quando fez o uso dele hoje, que o quadro ainda possui um efeito potente em sala de aula, sendo assim, ainda é um excelente recurso no processo de ensino-aprendizagem (diário de campo de um aluno).

Uma ruptura a-significante (DELEUZE; GUATTARI, 1995) na tessitura de nossa cartografia conceitual. Aqui o rizoma é um dispositivo que nos coloca problemas para traçar as linhas de forças. Como um modo de realização, um rizoma, "[...] não começa nem conclui, ele se encontra sempre no meio, entre as coisas" (DELEUZE; GUATTARI, 1995, p. 37). Um rizoma pode ser rompido, atravessando e rompendo as estruturas dadas. "Todo rizoma compreende linhas de segmentaridade segundo as quais ele é estratificado, territorializado, organizado, significado, atribuído, etc..; mas compreende também linhas de desterritorialização pelas quais ele foge sem parar" (DELEUZE; GUATTARI, 1995, p. 18). Uma das questões potentes do conceito de rizoma é colocar em análise o domínio das dicotomias - pensamento e ser, sujeito e objeto, professor e aluno. É afirmálo como "um caso de sistema aberto" (DELEUZE; GUATTARI, 1995, p. 18). Um sistema que repudia causalidade linear e transforma a noção de tempo. Deste modo, o rizoma aparece como condição dos regimes de forças e formas existentes. Trabalhar com o conceito de rizoma é afirmar que há outro domínio, que excede o domínio das formas dadas, onde se mistura o que era em aparência distinto, onde se conecta o que permanecia separado e, por isto, pode ser inventado.

Parafraseando Deleuze e Guattari (1995), uma formação não é a imagem do mundo segundo uma crença enraizada. Ela faz rizoma com o mundo, há evolução a-paralela da formação e do mundo. A formação assegura a desterritorialização do mundo, mas o mundo opera uma reterritorialização da formação, que, por sua vez, se desterritorializa em si mesma no mundo. Usar o quadro negro como um quadro comparativo é um modo representacional e instituído de viver o processo de ensino e de aprendizagem. Ele está colocado como um modo territorializado da formação. Em que medida acontece no dispositivo um jogo de forças? Mas é possível fazer, no contexto do dispositivo, um jogo de forças com as formas dadas, e evidenciar outros modos de operar com as linhas do dispositivo que o coloquem na ordem da invenção. 
Pintar as forças, este é um desafio de uma cartografia conceitual. Na formação de professores, tanto como na arte, não se trata de reproduzir ou inventar formas, mas de capturar forças. É por isso que nenhuma formação é figurativa. Como na célebre frase de Paul Klee (apud DELEUZE, 2007), "não apresentar o visível, mas tornar visível". Com os conceitos e autores que trabalhamos é possível dizer que a tarefa da formação de professores, em geral, e do estágio supervisionado, em especial, é definida como a tentativa de tornar visível forças que não são visíveis.

No entanto, esta não é uma operação fácil. Exige, tanto do educador como do formando, o manejo de ferramentas que possibilitem análises e trabalhos em territórios moventes, como é o campo da educação e da escola. Aqui, o grau de abertura, como princípio do método da cartografia destacado por Rolnik (2006), evidenciava a necessidade de trabalhar com ferramentas com as quais seria possível a análise da produção de subjetividade, que possui como características o movimento, a transformação, a processualidade. Kastrup e Barros (2009, p. 76) levantam questões que nos forçam a pensar:

A subjetividade é refratária a um método de investigação que vise representar um objeto, e requer um método capaz de acompanhar o processo em curso. As questões que se colocam são: como encontrar um método de investigação que expresse o processo que está em andamento? Como não limitar nossa investigação aos produtos desse processo? Trabalhando com um objeto em movimento, como não perdê-lo em categorias fixadas, que deixam fora da cena o fluxo processual no qual as subjetividades foram produzidas?

Questões pertinentes para o campo da formação de professores, pois há neste campo a necessidade de ratificar a importância urgente de forjar pesquisas que acompanhem o devir dos processos de subjetivação que ocorrem no "entre" de uma constituição de elementos, forças ou linhas que atuam simultaneamente. Pesquisas que façam operar deslocamentos e se coloquem a investigar o que afeta os formandos e os formadores, implicando-os com um exercício de problematização, com a produção de outros sentidos de formar, de agir e de viver.

Para Deleuze (2007), apresentar o movimento é um dos problemas que os artistas enfrentam para "tornar" visíveis forças que não são visíveis. Mas na formação, para que o educador torne visível as forças que estão invisíveis, ele precisa operar na desconstrução dos apriorismos que povoam com intensidade $o$ território do estágio, da escola e da formação.

A partir desse contato com a escola é possível definir melhor o que cada um quer de fato para si. Muitas vezes, ou melhor, quase sempre, operamos mediados por um mundo idealizado e nos vemos completamente perdidos diante do movimento real, da repetição e da diferença, nos diria Deleuze. Ouvi muitas falas de decepção. A decepção só existe quando criamos 
expectativa, ou seja, quando se opera por representações ideais de aluno, de escola, de aprendizado. De fato, alguns colegas me relataram um tipo ideal de aluno, aquele que fica quieto. $\mathrm{E}$ um tipo de aprendizado ideal, que se daria a partir de algo. $\mathrm{O}$ que me serviu neste estágio foi observar o quanto as pessoas operam pela lógica da representação (relatório de aluno).

Resistir à ordem armada da representação e forjar mundos outros é um desafio colocado, tanto pelos conceitos trabalhados no decorrer do semestre, como pelas escrituras dos alunos e do professor na expressão da experiência. E aqui, experiência toma corpo e é expressa por aquilo que nos passa, nos afeta e nos transforma (LARROSSA, 2004). O desafio é tensionar a noção constituída por uma heterogestão, para poder deslocar-se e forjar uma autogestão. Assim, assumir o desafio da constituição de uma cartografia conceitual produzida na disciplina Estágio Supervisionado I mostrou a necessidade de fazer a disciplina com diferentes dispositivos que expressem a tensão do cotidiano intenso e vivo da escola e da formação. Dar visibilidade às práticas efetivas propicia que os movimentos aconteçam utilizando diferentes linhas, que podem ser encontradas nos discursos e nos gestos cotidianos para se afastar e se diferenciar, produzindo um jogo onde é preciso retomar o problema das forças, do afrontamento, pelas análises num nível extraordinariamente baixo, ínfimo, cotidiano.

Desse modo, uma cartografia conceitual funciona como um instrumento, num processo artesanal que produz efeitos. Por isso, afirmo com este trabalho a necessidade de evidenciar que "[...]a enorme dificuldade seja instantânea: transpor a primeira impressão. Esse falso impostor não me vencerá" (CASARES, 2006, p. 27).

\section{Problema político do estágio SuPervisionado e uma FormaÇão}

\section{INVENTIVA DE PROFESSORES: ALGUMAS CONTRIBUIÇÕES PARA INSISTIR NAS}

\section{PERSPECTIVAS MICROPOLÍTICAS}

Ao longo deste texto, procurei deixar claro que formação inventiva, cartografia e pesquisa-intervenção não são um conjunto de regras para serem aplicadas, nem um saber pronto para ser transmitido ao futuro professor. Sendo assim, a feitura da tarefa de um professor passa por um aprendizado singular - estágio que não é questão de aquisição de um saber para solucionar um problema, nem de transmissão de informação. O aprendizado na disciplina Estágio Supervisionado é um problema político, micropolítico, pois ele dá ênfase às análises das circunstâncias em que uma formação inventiva é produzida, aos modos de subjetivação forjados, à tensão gerada numa multiplicidade de formas e forças, molares e moleculares e, em especial, aos diferentes conhecimentos criados em formação.

No contexto da micropolítica, é possível experienciar uma formação que se compõe de várias dimensões, linhas que expressam os deslocamentos de formação e seus efeitos atuando no estágio, nos caminhos escolhidos, nas práticas que fazem da formação uma obra aberta (DIAS, 2008). E é no bojo de constituição, 
sempre provisória, dessa obra aberta que se evidenciam os modos em que é possível distinguir uma formação como política, mais especificamente micropolítica, de uma formação que é pensada como uso legítimo da pretensão de abuso de poder de uma técnica. E, neste sentido, a noção de movimento ganha consistência nos deslocamentos entre a micro e a macropolítica. Tais deslocamentos não se fazem pela negação, mas pela afirmação vinculada à potência constituída nas experiências que criam sentidos na vida e na formação.

O que uma formação inventiva pensada numa micropolítica sugere, então, é a problematização da relação saber-poder-desejo no seio das cartografias das lutas específicas, de um exercício e um ensaio do agenciamento entre estágio, práticas e experiências locais. Desta maneira, ao habitar o território do estágio supervisionado na formação de professores, posso forjar outras análises e perguntar: o que a disciplina de estágio, pensada no contexto da micropolítica, pode evidenciar no campo da formação de professores? Em que sentido a ideia de estágio numa micropolítica auxilia na trajetória de professores e alunos ao lidar com as imprevisibilidades do cotidiano? Estas são apenas algumas das questões que atravessam este trabalho e auxiliam a pensar o deslocamento entre a micro e a macropolítica circunscritas ao campo da formação de professores em geral, e à disciplina de Estágio Supervisionado em especial.

Como funcionam os vetores que entram na formação de professores? $\mathrm{Da}$ mesma forma, como estão sendo criadas macropolíticas no campo da formação de professores, não estariam também sendo inventadas cotidianamente novas modalidades de luta micropolíticas? Como estas lutas estão sendo fabricadas? O que há de comum entre elas? Há ferramentas para o enfrentamento dessas lutas?

Uma formação que se une a uma micropolítica, então, forja desaprendizagens nas práticas e nos discursos instituídos e hegemônicos, e propõe uma atuação transformadora na/da realidade sociopolítica da formação. Como dizem Rocha e Aguiar (2003, p. 67), uma micropolítica substitui a fórmula "conhecer para transformar" por "transformar para conhecer". Tal fórmula traz desafios teórico-metodológicos e práticos para uma ação inventiva nos diferentes domínios da escola e da vida.

Desde o início de 2009, venho forjando na disciplina Estágio Supervisionado uma prática de menos tutela e mais abertura para a constituição de uma obra aberta. Apresentei, aqui, uma cartografia passando por diferentes domínios do conhecimento: formação inventiva, políticas de cognição, micropolítica, cartografia, pesquisa-intervenção, estética da existência. Em curso, afirmei o desafio de pensar em ferramentas de trabalho para um campo turbulento como o da formação e o da escola. Os métodos da cartografia e da pesquisa-intervenção e a transversalidade entre as disciplinas funcionam como ferramentas de trabalho para o formando e para o professor, que desestabilizam o que se delimita como campo de uma disciplina - Estágio Supervisionado. A ideia de desestabilização da disciplina emerge do plano de constituição dos diferentes domínios de conhecimentos em que as dicotomias - professor-aluno, ensino-aprendizagem, teoria- 
prática, escola-universidade - dão lugar aos híbridos, e as fronteiras disciplinares apresentam seus graus de abertura, por onde os saberes se interrogam e as práticas enunciam suas complexidades.

Assumir a disciplina Estágio Supervisionado numa dimensão micropolítica e com as ferramentas teórico metodológicas da cartografia e da pesquisa-intervenção nos compromete, portanto, com a produção de uma política de cognição e uma formação inventiva. Estas evidenciam que o conhecer não se limita a um processo de solução de problemas, a uma adoção de um modelo, mas envolve uma posição em relação ao mundo e a si mesmo, uma atitude, um ethos, como dito anteriormente. Neste sentido, como política, uma formação inventiva assume um conhecer que se afirma como uma inscrição corporal. Para tanto, não basta somente ler os textos e os livros e replicar ou aplicar os temas aprendidos na escola. É preciso praticar, ir à escola habitando o seu território, seguir processos, lançar-se na constituição de novas estratégias de aprendizagem e de ensino, experimentar dispositivos, estar atento àquilo que nos acontece, experimentar deslocamentos de pontos de vista e praticar a escrita, levando em conta que a produção do estágio supervisionado e da formação assumem uma dimensão coletiva.

Nesse sentido, se o desejo é de uma formação micropolítica para o enfrentamento da complexidade da escola, se quisermos mudar a escola, também temos de mudar a nós mesmos, nossos modos de formar, nossas ferramentas de análise e de intervenção. Forjando ferramentas de luta, enfrentando diversos riscos, afirmando o rigor das escolhas teórico metodológicas e a necessidade permanente de ensaiar seus usos e estar atenta para a análise dos efeitos em nós, nos formandos e nas escolas que nos atravessam. Já que o problema político do estágio supervisionado e o de uma formação inventiva assumem o esforço da criação de uma obra aberta. E, como numa criação em arte, as obras são sempre efeitos dos riscos e da insistência de viver uma experiência. Para terminar, retomo a discussão de Deleuze (2007) sobre arte. Ele diz que o desafio em arte é dar visibilidade às forças que não estão visíveis. Na pintura, tal desafio é superado sobretudo quando o artista enfrenta o problema do movimento. Penso que esta é uma questão que precisa ser enfrentada tanto na formação como na concepção do estágio supervisionado: como numa estética da existência, pensar na formação como a constituição de um território em movimento que luta por ser usina e usuária de um conhecimento vivo e incorporado.

\section{Notas}

${ }^{1}$ Referentes à disciplina Estágio Supervisionado I, ministrada na FFP/UERJ no primeiro semestre de 2009. O trabalho desta disciplina acontece no contexto de produção do projeto "Articulando universidade e a escola básica no Leste Fluminense: investigando o estágio docente como política de formação inicial de professores/PRODOCÊNCIA/CAPES".

${ }^{2}$ Esta noção é analisada nas pesquisas: "Formação inventiva: experiência e políticas cognitivas na formação de professores" e "Formação inventiva de professores e políticas de cognição como dispositivos para a criação do conselho escolar do Colégio Estadual Conselheiro Macedo Soares". Ambas contam com financiamento da FAPERJ e são desenvolvidas na FFP/UERJ.

${ }^{3}$ Francisco Varela (1994) faz um histórico das ciências cognitivas delineando quatro etapas: cibernética, cognitivismo, conexionismo e enação, que traçam o percurso dos estudos do conhecer e da mente humana pelas ciências cognitivas. Vale destacar que o desafio deste autor é colocar 
em análise as formas de conhecer dadas a priori, para dar visibilidade a um modo de conhecer sem representação, incorporado, chamado de enação. Há assim uma coemergência entre o si e o mundo. Para maiores análises, ver Varela; Thompson; Rosch (2003).

${ }^{4} \mathrm{Um}$ modo naturalizado que expressa uma formação universal e que se dá por aplicação de um saber prévio generalizante.

5Como uma "imagem dogmática do pensamento" (DELEUZE, 1988), o pressuposto não é posto em discussão e opera como princípio do pensamento.

${ }^{6}$ Esta noção é pensada por meio da perspectiva de Deleuze e Guattari (2002), como um território de passagem e de produção de subjetividade como efeitos de signos expressivos.

${ }^{7} \mathrm{O}$ percurso da disciplina se organizou da seguinte forma: 1 - análise teórico-social dos textos: Deleuze e Guattari (1995); Rolnik (2006); Kastrup (2008); Rocha e Uziel (2008); Lourau (1993); 2 - elaboração de uma proposta de trabalho para a escola-campo; 3 - idas à escola para efetivar a proposta elaborada e 4 - análise dos diários de forma coletiva. É importante destacar que a produção dos diários de campo foi tarefa permanente no decorrer do semestre.

${ }^{8}$ Ao analisar a filosofia de Foucault, Deleuze (1996) diz que ela é feita por dispositivos concretos, compostos por linhas de natureza diferentes: linhas de visibilidade, linhas de enunciação, linhas de forças e linhas de subjetivação. Tais linhas seguem direções e traçam processos que estão sempre em desequilíbrio, pois seu pensamento não evolui, mas procede por crises e choques. Por isso Foucault trabalha em termos de linhas que se movimentam. Das diferentes linhas decorrem efeitos importantes : primeiro, o repúdio pelos universais de reflexão, de comunicação, de consenso; e, em seguida, a afirmação de que cada dispositivo é uma multiplicidade que opera em devir, expressando uma estética dos modos de existência. O segundo desvio fala do Eterno para apreender o novo. Distinguindo o novo da moda, Deleuze (1996, p. 94) prossegue a análise por outros percursos: "Não é predizer, mas estar atento ao desconhecido que bate à porta". Esses efeitos propagam diferenças na produção da existência, não de um Eu universal e predeterminado, mas na produção de subjetividade que os dispositivos definem pelo que eles detêm de novidade e de invenção, e "[...] que ao mesmo tempo marca a sua capacidade de se transformar, ou de desde logo se fender em proveito de um dispositivo futuro" (DELEUZE, 1996, p. 92).

\section{REFERÊNCIAS}

CASARES, A. B. A invenção de Morel. 3. ed. São Paulo: C. Naify, 2006.

DELEUZE, G. O que é um dispositivo? In: . O mistério de Ariana. Lisboa: Veja, 1996. p. 83-96.

DELEUZE, G. Diferença e repetição. Rio de Janeiro: Graal, 1988.

DELEUZE, G. Foucault. São Paulo: Brasiliense, 2005.

DELEUZE, G. Lógica da sensação. Rio de Janeiro: J. Zahar, 2007.

DELEUZE, G.; GUATTARI, F. Rizoma. In: esquizofrenia. Rio de Janeiro: 34, 1995. v. 1. p. 7-37. . Mil platôs: capitalismo e

DELEUZE, G.; GUATTARI, F. Mil platôs: capitalismo e esquizofrenia. São Paulo: 34, 2002. v. 4.

DELEUZE, G.; PARNET, C. Diálogos. Lisboa: Relógio D’Água, 2004.

DIAS, R. O. Deslocamentos na formação de professores: aprendizagens de 
adultos, experiência e políticas cognitivas. 2008. 224 f. Tese (Doutorado em Psicologia) - Instituto de Psicologia, Universidade Federal do Rio de Janeiro, Rio de Janeiro, 2008.

DIAS, R. O. Formação inventiva de professores e políticas de cognição. Informática na Educação: teoria e prática, Porto Alegre, v. 12, n. 2, p. 164-174, jul./dez. 2009. Disponível em: <http://www.seer.ufrgs.br/index.php/InfEducTeoriaPratica>. Acesso em: 30 nov. 2010.

FOUCAULT, M. História da sexualidade: o cuidado de si. Rio de Janeiro: Graal, 1985. v. 3.

FOUCAUlT, M. A hermenêutica do sujeito. São Paulo: Martins Fontes, 2004.

FOUCAULT, M. Uma estética da existência. In: Ética, sexualidade, política. 2. ed. Rio de Janeiro: Forense Universitária, 2006a. v. 5, p. 288293. Coleção Ditos e Escritos.

FOUCAULT, M. A ética do cuidado de si como prática da liberdade. In:

Ética, sexualidade, política. 2. ed. Rio de Janeiro: Forense Universitária, $\overline{2006 b}$. v. 5, p. 264-289. Coleção Ditos e Escritos.

GUATTARI, F.; ROLNIK, S. Micropoliticas: cartografias do desejo. 7. ed. Petrópolis: Vozes, 2005.

KASTRUP, V. O método da cartografia e os quatro níveis da pesquisaintervenção. In: CASTRO, L. R.; BASSET, V. L. (Org.). Pesquisaintervenção na infância e juventude. Rio de Janeiro: Nau, 2008. p. 465481.

KASTRUP, V. A invenção de si e do mundo: uma introdução do tempo e do coletivo no estudo da cognição. Campinas: Papirus, 1999.

KASTRUP, V.; TEDESCO, S.; PASSOS, E. Políticas da cognição. Porto Alegre: Sulina, 2008.

KASTRUP, V.; BARROS, R. B. Movimentos-funções do dispositivo na prática da cartografia. In: PASSOS, E.; KASTRUP, V.; ESCÓSSIA, L. Pistas do método da cartografia: pesquisa-intervenção e produção de subjetividade. Porto Alegre: Sulina, 2009. p. 76-91.

LARROSA, J. Linguagem e educação depois de Babel. Belo Horizonte: Autêntica, 2004. 
LOURAU, R. Análise Institucional e práticas de pesquisa. Rio de Janeiro: UERJ, 1993.

PASSOS, E.; KASTRUP, V.; ESCÓSSIA, L. Pistas do método da cartografia: pesquisa-intervenção e produção de subjetividade. Porto Alegre: Sulina, 2009.

PÉLBART P.P. Elementos para uma cartografia da grupalidade. In: SAADI, F.; GARCIA, S. (Org.). Próximo ato: questões da teatralidade contemporânea. São Paulo: Itaú Cultural, 2008. Disponível em: <http://www.itaucultural.org.br/ proximoato/pdf/textos/textopeterpelbart.pdf>. Acesso em 24 maio 2010.

ROCHA, M. L. A formação como acontecimento: solidão, pensamento e autogestão. In: MACHADO, A. M.; FERNANDES, A. M. D.; ROCHA, M. L. (Org.). Novos possíveis no encontro da psicologia com a educação. São Paulo: Casa do Psicólogo, 2007. p. 37-48.

ROCHA, M. L.; AGUIAR, K. F. Pesquisa-intervenção e a produção de novas análises. Psicologia: ciência e profissão, Brasília, v. 23, n. 4, p. 64-73, out./dez. 2003.

ROCHA, M. L.; AGUIAR, K. F. Entreatos: percursos e construções da psicologia na rede pública de ensino. Revista Estudos e Pesquisas em Psicologia, Rio de Janeiro, UERJ, ano 10, n. 1, p. 68-84, 2010. Disponível em: <http://www.revispsi. uerj.br/v10n1/artigos/pdf/v10n1a06.pdf>. Acesso em: 10 maio 2010.

ROCHA, M. L.; UZIEL, A. P. Pesquisa-intervenção e novas análises no encontro da psicologia com as instituições de formação. In: CASTRO, L. R.; BASSET, V. L. (Org.). Pesquisa-intervenção na infância e juventude. Rio de Janeiro: Nau, 2008. p. 532-558.

ROLNIK, S. Cartografia sentimental: transformações contemporâneas do desejo. Porto Alegre: Sulina, 2006.

VARELA, F. Conhecer: as ciências cognitivas, tendências e perspectivas. Lisboa: Instituto Piaget, 1994.

VARELA, F. J.; THOMPSON, E.; ROSCH, E. A mente incorporada: ciências cognitivas e experiência humana. Porto Alegre: Artmed, 2003.

Recebido em: 31 de janeiro de 2011

Aceito em: 04 de maio de 2011 